\title{
HOMICIDE IN U.S. WORKPLACES: A STRATEGY FOR PREVENTION AND RESEARCH
}

Project Officers: Catherine A. Bell and E. Lynn Jenkins

This report summarizes the deliberations of participants of a workshop on occupational homicide prevention that was held in Washington, DC on July 23-24, 1990. The workshop and this report were sponsored by the National Institute for Occupational Safety and Health.

This report was transcribed and edited by Mary Ann Fenley, Fenley Communications, under Purchase Order \$0-44850.

U.S. DEPARTMENT OF HEALTH AND HUMAN SERVICES

Public Health Service

Centers for Disease Control

National Institute for Occupational Safety and Health

Division of Safety Research

Morgantown, WV 26505 


\section{DISCLAIMER}

Sponsorship of this workshop and proceedings does not constitute endorsement of the views expressed or recommendation for the use of any commercial product, commodity or service mentioned. The opinions expressed in this document are those of the participants and not necessarily those of the sponsors.

The research recommendations are not to be considered as final statements of NIOSH policy or of any agency or individual who was involved. They are intended to be used in advancing the knowledge needed for worker protection. 


\section{CONTENTS}

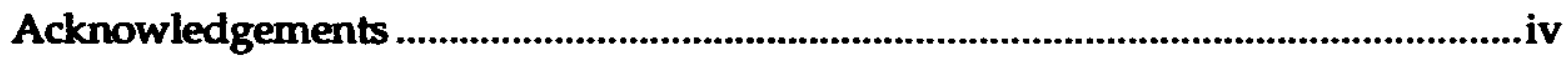

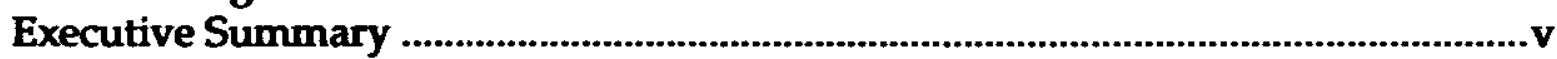

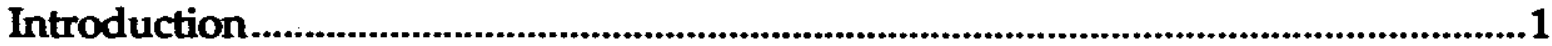

Surveillance and Epidemiologic Research Needs .................................................................

Research Areas Identified by Existing Data Sources........................................................3

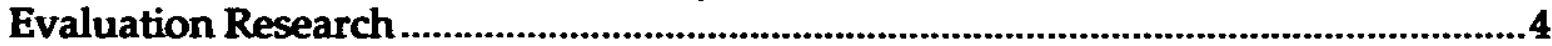

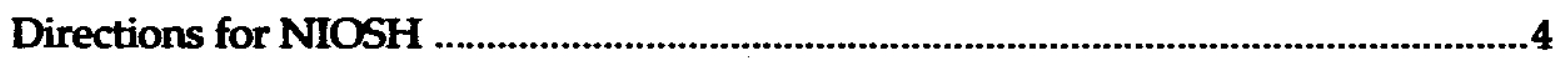

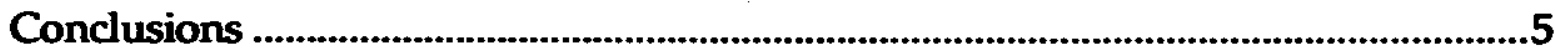

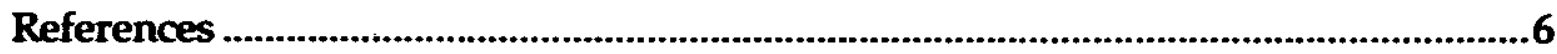

List of Workshop Participants .......................................................................................... 


\section{ACKNOWLEDGEMENTS}

The initial text of this document was compiled by Mary Ann Fenley of Fenley Communications, Inc. Revisions and subsequent versions were compiled by E. Lynn Jenkins, Timothy J. Pizatella, and Nancy A. Stout of the National Institute for Occupational Safety and Health, Division of Safety Research. 


\title{
HOMICIDE IN U.S. WORKPLACES:
}

\section{A STRATEGY FOR PREVENTION AND RESEARCH}

\author{
EXECUTTVE SUMMARY
}

Homicide was the third leading cause of occupational injury death in the U.S. for the period from 1980 through 1985, accounting for nearly $13 \%$ of the nation's total deaths from trauma in the workplace. Homicide was the manner of death for $12 \%$ of the men and $42 \%$ of the women who died from injuries sustained in U.S. workplaces during the 6-year period for which data were available at the time of the workshop.

These data from the National Institute for Occupational Safety and Health (NIOSH) have brought the problem of workplace homicide, which had not previously been fully recognized by the public health community, into sharp focus.

In July 1990, NIOSH convened a panel of experts in the field of interpersonal violence to review the NIOSH data to identify areas of concern and to make recommendations for future research. This document summarizes those discussions, which may serve as the foundation for the development of a national strategy for prioritizing research and targeting interventions to prevent work-related homicides.

Workshop participants discussed 1) limitations of available data, 2) important research issues, 3) areas where further research is needed, and 4) evaluation of known prevention strategies.

In order to reduce workplace homicide, all organizations and individuals who have responsibilities in the area must work within the framework of a cooperative national effort. A comprehensive national strategy aimed at reducing workplace homicide must include a coordinated program of surveillance, epidemiology, intervention strategy development, efficacy evaluation, and dissemination. 

HOMICIDE IN U.S. WORKPLACES:

A Strategy for Prevention and Research

\section{Introduction}

Homicide was the third leading cause of occupational injury death in the U.S. for the period from 1980 through 1985, accounting for nearly $13 \%$ of the nation's total deaths from trauma in the workplace. Homicide was the manner of death for $12 \%$ of the men and $42 \%$ of the women who died from injuries sustained in U.S. workplaces during the 6-year period for which data were available at the time of the workshop (National Traumatic Occupational Fatalities (NTOF)). ${ }^{1}$

The average annual workplace homicide rates for men and women during 1980 to 1985 were 1.2 and 0.4 deaths per 100,000 workers, respectively, or 0.8 deaths per 100,000 members of the workforce, annually. The NTOF data also indicate that $73 \%$ of workplace homicide victims died from gunshot wounds. Additionally, while over one-quarter of workplace homicide victims were 25-34 years of age, workplace homicide rates were highest among those 65 years of age and older ( 2.7 deaths per 100,000 workers).

At the industry division level, $33 \%$ of workplace homicide victims were employed in retail trade, $19 \%$ in service industries, and $11 \%$ in public administration. At 2.1 deaths per 100,000 workers, public administration was the industry division with the highest rate of workplace homicide. Law enforcement officers constituted $83 \%$ of this category.

Analysis by more detailed industry sectors indicates that local passenger transportation (Standard Industrial Classification (SIC) 41) was one of the most hazardous in terms of workplace homicide, with a rate of 3.5 per
100,000 workers. Taxi cab drivers accounted for $47 \%$ of the deaths in this industrial group. Retail food sales (SIC 54) had a workplace homicide rate of 2.2 deaths per 100,000 workers.

It should be noted that homicide data were not available from four states-New York, Oklahoma, Nebraska, and Louisiana-for the period included in these analyses. These states account for approximately 10 percent of the U.S. population. More recently, these states have begun to submit these data; but for $\mathbf{1 9 8 0}$ through 1985, the real number of workplace homicides in the U.S. was undoubtedly greater than NTOF data indicate. Thus, although homicide had not been previously recognized by the publichealth community as a leading cause of workplace injury death, homicide is clearly a significant safety problem in the nation's workplaces.

In July 1990, NIOSH convened a panel of experts in the field of interpersonal violence to review NTOF data to identify areas of concern and to make recommendations on areas for future research. (The workshop participants are listed in the Appendix.) This document is a summary of those discussions, and should serve as the foundation for the development of a national strategy for use in prioritizing research and targeting interventions to prevent work-related homicides.

Suroeillance and Epidemiologic Research Needs

The design of analytic studies and prevention efforts directed toward workplace homicide is often hampered by limitations inherent in available data sources. Currently, death certificates are the primary source of national data regarding workplace homicide. The Federal Bureau of Investigation (FBI) Supplementary Homicide Reports (SHR) ${ }^{2}$ do not include 
an indicator of work-relatedness, and police records are not centralized nor automated."

Existing denominator data for the calculation of rates include the Bureau of the Census County Business Patterms ${ }^{3}$ and Census of Agriculture4 and the Bureau of Labor Statistics' Employment and Eamings (based on the Current Population Survey). 5 These sources tabulate economicinformation for the nation's workforce and provide the total number of employed persons (but not full-time equivalents) by industry, occupation, age, sex, and race. Some of the limitations of the available data sources seen as most significant by workshop participants were:

1) The leoel of detail necessary to describe occupations within major industrial classifications is often lacking on death certificates.

Industry and occupation information provided on death certificates reflects "usual" occupation and industry and is provided by funeral directors. While guidelines exist for the completion of this item, the level of detail varies greatly. For example, retail food stores have an occupational homicide rate of 2.2 per 100,000 workers. The data indicate that $34 \%$ of the victims in this industry were cashiers, but do not allow reliable specification of how many were cashiers/clerks in convenience stores.

2) The reporting of place of injury is not consistent or perhaps accurate on death certificates.

There is an item on death certificates which asks for information regarding the location of the injury, but the information collected through this mechanism varies from a specific street address to a general description of the place of occurrence (e.g., a farm or ranch). Often analysis is hampered because entries

It should be noted that the FBI is revising data collection efforts under its new National Incident-Based Reporting System and these changes should be monitored for application to wodplace homicide surveillance. are categorized as "public place" or "other specified place" - a category which includes all entries for which the name of a building or an exact location was listed on the death certificate.

3) There are no nationally standardized guidelines for completion of the work-related item on death certificates.

No standardized guidelines are currently in use regarding the completion or querying of the "injury at work?" item on death certificates. The responses to this item rely on individual certifier interpretation of the meaning of the item; thus, certifiers may indicate "injury at work?" as "yes" simply because a death occurred in the workplace, regardless of whether it was a direct result of workrelated activities.

4) Accurate classification of some occupations may be difficult due to ambiguity and potential misinterpretation of narratioe entries.

For example, there are workers in industries such as housekeeping who may be classified as laborers or as service personnel. The Bureau of the Census industry and occupation classification structure is sometimes limited when applied to death certificate data. The assignment of codes can be modified by the inclusion or exclusion of a single term. For example, if theoccupation entry from a certificate is "cleaner" with no industry specified, the occupation code assigned would be 889 (laborer, not specified), whereas, if the entry on the certificate was "housekeeper" with no industry specified, the code assigned would be 469 (personal service occupations, not elsewhere classified).

5) Precipitating eoents are not usually described on death certificates.

Death certificates were designed to function as administrative information collection 
forms and as such do not collect the epidemiologic information necessary to describe the circumstances surrounding fatal events. Death certificates do contain an item which asks the certifier to provide a brief description of how the fatal injury occurred, but descriptions must be brief and typically do not contain the level of detail necessary to reconstruct the sequence of events leading to the death.

6) Exposure data needed to compute releoant risks are not available.

While available data allow description of the workforce by general demographic and employment characteristics, there are no available data to describe the number of persons in specific occupations by time of day worked or number of hours worked-e.g., day, evening, and night shifts and part-time versus fulltime. Data on the urban versus rural distribution of injuries are not reliably available from existing data sources. Clear, consistent classification of security personnel is necessary.

7) Releoant data sources such as NTOF and the FBI SHR data have not been linked.

Detailed information regarding homicide events as well as victims and offenders is available in the FBISupplementary Homicide Reports. However, the data contain noindication of the work-relatedness of events. Therefore, the FBI data must be linked with a data source that identifies workplace homicides, such as NTOF. For confidentiality reasons, both NTOF data and the FBI data have been stripped of personal identifiers. As a result, matching cases from these two data sets may be difficult, at best.

8) Information on homicide in the U.S. population from the National Center for Health Statistics (NCHS) Vital Statistics Mortality data files has not been compared to information on workplace homicide from NTOF.
Analysis of this type would allow description of the relative risk of occupational homicide to non-occupational homicide.

9) No national data source exists that allows description of nonfatal injuries sustained as a result of violence in the workplace and also contains information on occupation, industry, and detailed circumstances of the eoent.

Limited data on nonfatal injury sustained as a result of violence or assault is available from the National Crime Survey conducted by the Bureau of the Census for the Bureau of Justice Statistics. However, information on the workrelatedness of violence and assault is not automated and is limited to data collected prior to 1986.

Research Areas Identified by Existing Data Sources

Existing data, even with their limitations, indicate certain areas in particular need of further research. Workshop participants felt the important research issues included:

1) What roles do interaction with the public, the exchange of money, and evening employment play in work-related homicide?

Studies in limited geographic areas ${ }^{6-9}$ have indicated these factors may be associated with the risk of workplace violence, but analytic epidemiologic studies are necessary to quantify this risk.

2) What is the distribution of long-haul truck drivers and short-haul or delivery truck drivers in mortality statistics?

NTOF data for 1980-85 indicate that motor freight transportation workers were at increased risk (1.6 deaths per 100,000 workers, a rate twice as high as the average), ${ }^{*}$ but the

Subsequent scrutiny of the NTOF deaths among transport operatives revealed that taxi cab drivers are at substantially greater risk of homicide than are truck drivers. 
level of detail contained on death certificates does not allow reliable quantification of the distribution of long-haul versus short-haul or delivery truckdrivers in the mortality figures.

3) What proportion of truckers in mortality statistics had receioed cash for their deliveries and, therefore, had money with them?

Due to the lack of data on both the presence of cash and the distribution of truck drivers by truck/activity type, further research is needed to adequately describe the risk in this population. Short-haul and delivery truck drivers may be more likely to carry cash.

4) What are the specific risk factors for homicides among females and the elderly?

Although the rate of occupational homicide is three times higher for males than for females, the proportion of women killed in the workplace as a result of homicide $(\mathbf{4 3 \%})$ is a remarkable finding which merits further investigation. ${ }^{10}$ In addition, the high rate of workplace homicide to workers 65 years of age and older (2.0 per 100,000 workers according to NTOF data for 1980 through 1988 ) requires additional research.

5) What is the urban/rural distribution of workrelated homicide?

Differences in work-related homicide rates between urban and rural areas need to be identified, particularly in terms of industry and occupational categories.

6) What role do multiple or repeat violent victimizations at specific sites within an industry play in work-related homicides within that industry?

Preliminary studies have suggested that there is a non-random distribution of violent crimes occurring at specific sites within an industry. Examination of the relationship of prior vic- timizations would be useful in studying subsequent work-related homicides.

\section{Evaluation Research}

Strategies designed to prevent occupational homicide that have been introduced in some limited geographic areas and in a few industries, need to be rigorously evaluated. Evaluation of the effectiveness of various strategies alone, and in combination with other efforts, is critical to the design of new strategies and to the development of a comprehensive workplace homicide prevention effort. Specifically, various environmental approaches such as improved lighting, locked drop-safes, work areas openly visible to the public, and increased staffing need to be evaluated singly and in combination. Behavioral strategies, such as training in conflict resolution and nonviolent response, should also be examined in detail to determine the salient features of training programs and approaches to implementation.

\section{Directions for NIOSH}

Recommendations for the direction of NIOSH efforts in occupational homicide research and prevention include the following:

1) Continue efforts to improve the quality of death certificate data, including the deoelopment of nationally standardized guidelines for the completion of the injury at work item and the improoement of occupation and industry coding of occupational homicide cases.

2) Conduct a 1-year census of occupational homicides working with local/state health departments and law enforcement agencies to obtain multiple data sources, e.g. death certificates, police reports, and medical examiner data, that prooide a more detailed description of the circumstances of the events. 
3) Compare homicide data from NCHS vital statistics data for the U.S. to NTOF data on workplace homicides in the U.S.

4) Match NTOF data on workplace homicides to the FBI SHR data to obtain details on the event, the victim and the offender.

5) Conduct and/or fund demonstration projects and evaluation research to determine the most effective intervention and prevention strategies.

6) Conduct and/or fund studies of the populations at risk specified above under Surveillance and Epidemiologic Research Needs (page 1).

7) Coordinate activities with the Bureau of Labor Statistics and the Bureau of the Census to identify changing employment and demographic patterns, especially with regard to part-time work.

8) Disseminate workplace homicide prevention information in a timely manner with particular attention to populations that may not be reached through traditional public health communication methods.

9) Explore the possibilities for regulation through the Occupational Safety and Health Administration (OSHA) to ensure safe workplace conditions.

As a short-term intervention, OSHA could be encouraged to use existing authority under Section 5(a)(1) of the OSH Act to enforce stateof-the-practice and consensus standards. The long-term intervention should involve development by NIOSH of the criteria for the establishment of OSHA standards to reduce the occurrence of homicide in U.S. workplaces.

10) Develop the institutional capacity to serve as the liaison with the many different groups involved in occupational homicide research and prevention.

11) Guide the creation of a small external review committee to reoiew available data on workplace violence and advise NIOSH on future directions.
12) Examine the possibilities for collection of data on morbidity sustained as the result of violence in the workplace.

Obtaining morbidity histories for given sites may allow special studies of high crime areas to determine if these sites experience a disproportionate number of homicides.

\section{Conclusions}

It is clear from available data that workplace homicide is a public health problem of significant proportion. It is also clear that in order to reduce workplace homicide, NIOSH must work with all of the constituents who have responsibilities in the area. Collaboration and coordination of research and intervention efforts will be needed, and should include other appropriate federal agencies such as OSHA; the Department of Justice; FBI; other centers within the Centers for Disease Control (CDC); and public and private sector constituents such as academia, industry associations, labor unions, professional societies, national associations, law enforcement groups, state and local advocacy groups, and the public health community at large. A comprehensive strategy aimed at reducing workplace homicide must include a coordinated program of surveillance, epidemiology, intervention strategy development, efficacy evaluation, and dissemination. 


\section{REFERENCES}

1. US. Department of Health and Human Services, Centers for Disease Control, National Institute for Occupational Safety and Health. National Traumatic Occupational Fatalities (NTOF) database. Division of Safety Research, Morgantown, West Virginia.

2. Federal Bureau of Investigation. Supplementary Homicide Report [Public use data tape and documentation.] Washington, D.C.

3. U.S. Department of Commerce, Bureau of the Census. County Business Patterns [state files and public use data tapes.] Washington, D.C.

4. U.S. Department of Commerce, Bureau of the Census. Census: 1982 Census of Agriculture [state files and public use data tapes.] Washington, D.C.

5. U.S. Department of Labor, Bureau of Labor Statistics. Employment and Earnings. Household data annual averages. 28(1), 1981;29(1), 1982;30(1), 1983;31(1), 1984;32(1), 1985; 33(1), 1986.

6. Davis H, Honchar PA, Suarez L [1987]. Fatal occupational injuries of women, Texas 1975-1984. Am J Public Health 77:1524-1527.

7. Davis H [1987]. Workplace homicides of Texas males. Am J Public Health 77:12901293.

8. Kraus JF [1987]. Homicide while at work: Persons, industries, and occupations at high risk. Am J Public Health 77:1285-1289.

9. Hales T, Seligman PD, Newman SC, Timbrook CL [1988]. Occupational injuries due to violence. J Occup Med 30:483-487.

10. Bell, CA [1991]. Female homicides in United States workplaces, 1980-1985. Am J Public Health 81:729-732. 


\section{LIST OF WORKSHOP PARTICIPANTS}

Catherine Bell, B.G.S. *

Division of Safety Research

National Institute for Occupational Safety and

Health

Centers for Disease Control

Morgantown, West Virginia

Thomas Bender, M.D., M.P.H.

Director, Division of Safety Research

National Institute for Occupational Safety and

Health

Centers for Disease Control

Morgantown, West Virginia

Rosemary Erickson, M.A.

Athena Research Corporation

Washington, D.C.

Jess Kraus, Ph.D.

School of Public Health

University of California at Los Angeles

Los Angeles, California

Roberta Lee, R.N., Dr. P.H.

University of Texas School of Nursing

University of Texas Medical Branch

Galveston, Texas

Colin Loftin, Ph.D.

Institute of Criminal Justice and Criminology

University of Maryland

College Park, Maryland

Jay Malcan, Ph.D.

Virginia Department of Criminal Justice

Services

Richmond, Virginia
James Mercy, Ph.D.

National Center for Environmental Health

and Injury Control

Centers for Disease Control

Atlanta, Georgia

Timothy Pizatella, M.S.

Division of Safety Research

National Institute for Occupational Safety and

Health

Centers for Disease Control

Morgantown, West Virginia

Jeffrey Roth, Ph.D.

Abt Associates, Inc.

Bethesda, Maryland

Paul Seligman, M.D., M.P.H.

Division of Surveillance, Hazard Evaluations, and Field Studies

National Institute for Occupational Safety and

Health

Centers for Disease Control

Cincinnati, Ohio

Margaret Zahn, Ph.D.

Department of Sociology and Anthropology

University of North Carolina in Charlotte

Charlotte, North Carolina

Franklin Zimring, J.D., M.P.H.

The Law School

University of California at Berkeley

Berkeley, California

- Now with the Environmental Protection Agency, Seattle, Washington 